\title{
Extremely drug-resistant NDM-9-producing ST147 Klebsiella pneumoniae causing infections in Italy, May 2020
}

\author{
Marco Falcone $^{1,2}$, Cesira Giordano ${ }^{2,3}$, Simona Barnini ${ }^{3}$, Giusy Tiseo ${ }^{1}$, Alessandro Leonildi ${ }^{3}$, Paolo Malacarne ${ }^{4}$, Francesco \\ Menichetti ${ }^{1}$, Alessandra Carattoli ${ }^{5}$ \\ 1. Infectious Diseases Unit, Department of Clinical and Experimental Medicine, University of Pisa, Pisa, Italy \\ 2. The authors contributed equally this article \\ 3. Microbiology Unit, Azienda Ospedaliera Universitaria Pisana, Pisa, Italy \\ 4. Department of Anaesthesia and Critical Care Medicine, Azienda Ospedaliera Universitaria Pisana, Pisa, Italy \\ 5. Department of Molecular Medicine, Sapienza University of Rome, Rome, Italy
}

Correspondence: Alessandra Carattoli (alessandra.carattoli@uniroma1.it)

Citation style for this article:

Falcone Marco, Giordano Cesira, Barnini Simona, Tiseo Giusy, Leonildi Alessandro, Malacarne Paolo, Menichetti Francesco, Carattoli Alessandra. Extremelydrug-resistant NDM-9-producing ST147 Klebsiella pneumoniae causing infections in Italy, May 2020. Euro Surveill. 2020;25(48):pii=2001779. https://doi.

org/10.2807/1560-7917.ES.2020.25.48.2001779

Article submitted on 09 Oct 2020 / accepted on 03 Dec 2020 / published on 03 Dec 2020

\begin{abstract}
A large outbreak of New Delhi metallo-beta-lactamase (NDM)-1-producing Klebsiella pneumoniae sequence type (ST) 147 occurred in Tuscany, Italy in 2018-2019. In 2020, ST147 NDM-9-producing K. pneumoniae were detected at the University Hospital of Pisa, Tuscany, in two critically ill patients; one developed bacteraemia. Genomic and phylogenetic analyses suggest relatedness of 2018-2019 and 2020 strains, with a change from NDM-1 to NDM-9 in the latter and evolution by colistin, tigecycline and fosfomycin resistance acquisition.
\end{abstract}

A large outbreak sustained by New Delhi metallo-betalactamase (NDM)-1-producing Klebsiella pneumoniae sequence type (ST) 147 occurred in Tuscany, Italy in 2018-2019 [1,2]. In 2020, NDM-9-producing K. pneumoniae were isolated in the same geographical area. In this study, comparisons at genomic level of these recent isolates with strains representative of the 20182019 outbreak were carried out. The 2020 strains were ST147 and had acquired resistance to colistin, tigecycline, and fosfomycin.

\section{Case reports}

In May 2020, two critically ill patients were respectively colonised or infected by extensively drug-resistant (XDR), NDM-9-producing $K$. pneumoniae at the University Hospital of Pisa, Tuscany, Italy.

The first patient $\left(\mathrm{P}_{1}\right)$ was admitted to the intensive care unit (ICU) of the hospital for a minor surgical intervention related to a cerebral trauma 1 year earlier. At admission, a rectal swab culture was positive for NDMproducing $K$. pneumoniae (strain $\mathrm{Kp}-\mathrm{P}_{1}$; identification by MALDI-ToF MS, Bruker Daltonics, Bremen, Germany).
Susceptibility to a series of antibiotics was assessed (Merlin ITGN Panel, Tecan automated system, Tecan Trading AG, Männedorf, Switzerland), using minimum inhibitory concentrations (MICs) breakpoints established by the European Committee on Antimicrobial Susceptibility Testing (EUCAST) [3]. The isolated strain resulted resistant to all tested antibiotics, including colistin, fosfomycin (agar-dilution method; $A D$ Fosfomycin, Liofilchem, Roseto degli Abruzzi, Italy) and tigecycline (Table 1). It was susceptible to cefiderocol (SensiTitre Cefiderocol MIC panel CMP1SHIH, Thermo Fisher, Waltham, MA, USA). No significant infections were diagnosed in this patient during the hospital stay.

A second patient $\left(\mathrm{P}_{2}\right)$ was admitted 5 days later to the same ICU because of a traumatic injury. The patient had no history of previous hospitalisation. Throat and rectum swabs taken at admission yielded cultures negative for carbapenem-resistant Gram-negative bacilli. A rectal swab taken on day 7 post admission, however, led to the detection of an NDM-producing K. pneumoniae by PCR for the bla ${ }_{\text {NDM }}$ gene. On day 13, the patient developed a central venous catheter-related bacteraemia due to NDM-producing $K$. pneumoniae (strain Kp- $\mathrm{P}_{2}$ ). The susceptibility profile of strain $\mathrm{Kp}-\mathrm{P}_{2}$ was identical to that of strain Kp-P1 (Table 1). Checkerboards were set up with twofold dilutions of aztreonam (ATM; 0.03 to $128 \mathrm{mg} / \mathrm{L}$ ) and ceftazidime-avibactam (CAZ-AVI; $1-0.25$ to $64-16 \mathrm{mg} / \mathrm{L}$ ) as previously described [4]: the combination resulted fully synergistic (fractional inhibitory concentration index, $\mathrm{FICl}=0.03$; Table 1) against strain $\mathrm{Kp}-\mathrm{P} 2$. The patient was treated with intravenous CAZAVI $2.5 \mathrm{~g}$ every 8 hours plus ATM $2 \mathrm{~g}$ every 8 hours. The clinical conditions rapidly improved but the patient had a second episode of bloodstream infection (BSI) 
Minimum inhibitory concentrations of ST147 NDM-producing Klebsiella pneumoniae strains described in this study, Pisa, Italy ( $\mathrm{n}=8$ strains)

\begin{tabular}{|c|c|c|c|c|c|c|c|c|}
\hline \multirow{2}{*}{ Antibiotic } & \multicolumn{8}{|c|}{$\begin{array}{l}\text { Klebsiella pneumoniae strains/isolates } \\
\text { Minimum inhibitory concentrations in } \mathrm{mg} / \mathrm{L}\end{array}$} \\
\hline & $\begin{array}{l}\mathrm{Kp}-\mathrm{P}_{1} \\
\mathrm{Kp}-\mathrm{P}_{2}\end{array}$ & $\mathrm{Kp}-8 \mathrm{Pi}$ & Kp-9Pi & Kp-11Pi & $\mathrm{Kp}-12 \mathrm{Pi}$ & $\mathrm{Kp}-14 \mathrm{Pi}$ & $\mathrm{Kp}-16 \mathrm{Pi}$ & $\mathrm{Kp}-17 \mathrm{Pi}$ \\
\hline Ceftazidime & $>128$ & $>128$ & $>128$ & $>128$ & $>128$ & $>128$ & $>128$ & $>128$ \\
\hline Cefepime & $>32$ & 32 & $>32$ & $>32$ & $>32$ & $>32$ & $>32$ & $>32$ \\
\hline Ceftriaxone & $>4$ & $>4$ & $>4$ & $>4$ & $>4$ & $>4$ & $>4$ & $>4$ \\
\hline Cefiderocol & 2 & NT & NT & NT & NT & NT & NT & NT \\
\hline Meropenem & $>8$ & 8 & 8 & 8 & 8 & 4 & 8 & 64 \\
\hline Imipenem & $>8$ & 4 & 8 & 8 & 8 & 4 & 16 & $>16$ \\
\hline Ciprofloxacin & $>2$ & $>2$ & $>2$ & $>2$ & $>2$ & $>2$ & $>2$ & $>2$ \\
\hline Levofloxacin & $>4$ & $>4$ & $>4$ & $>4$ & $>4$ & $>4$ & $>4$ & $>4$ \\
\hline Amikacin & $>16$ & $>16$ & $>16$ & $>16$ & $>16$ & $>16$ & $>16$ & $>16$ \\
\hline Gentamycin & $>4$ & $>4$ & $>4$ & $>4$ & $>4$ & $>4$ & $>4$ & $>4$ \\
\hline SXT & $>4$ & $>4$ & $>4$ & $>4$ & $>4$ & $>4$ & $>4$ & $>4$ \\
\hline Tigecycline & 2 & 0.25 & 0.25 & 0.5 & 0.5 & 0.25 & 1 & 0.25 \\
\hline Fosfomycin & $>128$ & $\leq 16$ & $\leq 16$ & $\leq 16$ & $\leq 16$ & $\leq 16$ & 32 & 16 \\
\hline Colistin & 16 & $<0.5$ & $<0.5$ & $<0.5$ & 16 & $<0.5$ & 16 & $<0.5$ \\
\hline Aztreonam & 132 & $>32$ & $>32$ & $>32$ & $>32$ & $>32$ & 132 & 132 \\
\hline Ceftazidime/avibactam & $>8 / 4$ & $>8 / 4$ & $>8 / 4$ & $>8 / 4$ & $>8 / 4$ & $>8 / 4$ & $>8 / 4$ & $>8 / 4$ \\
\hline $\begin{array}{l}\text { Ceftazidime/avibactam plus } \\
\text { aztreonam }^{\text {a }}\end{array}$ & $\mathrm{FICl} 0.03$ & Synergistic & NT & NT & NT & NT & NT & NT \\
\hline
\end{tabular}

ATM: aztreonam; AVI: avibactam; FICI: fractional inhibitory concentration index; MIC: minimum inhibitory concentration; NDM: New Delhi metallo-beta-lactamase; NT: not tested; SXT: sulfamethoxazole-trimethoprim.

MICs were obtained using the Merlin ITGN Panel, Tecan automated system, Tecan Trading AG, Switzerland.

${ }^{\text {a }} \mathrm{FICI}$ ATM MIC $=0.25 \mathrm{mg} / \mathrm{L}$ with $\mathrm{AVI}$ at concentration of $4 \mathrm{mg} / \mathrm{L}$.

by NDM-producing K. pneumoniae on day 56. A second course of CAZ-AVI plus ATM was initiated, the patient's condition improved leading to discharge from ICU after 69 days. No relapse of infection was observed after 30 days from discharge.

\section{Ethical statement}

The study was conducted according to the principles stated in the Declaration of Helsinki. The local Ethics Committee (Comitato Etico Area Vasta Nord Ovest) approved the study (IRB n 61185). Study participants signed the informed consent.

\section{Genomic analysis of the 2020-NDM-9 ST147 Klebsiella pneumoniae strains}

Genomic DNAs were purified from Kp-P1 and Kp- $\mathrm{P}_{2} K$. pneumoniae strains (Macherey Nagel DNA extraction kit, Düren, Germany) to build up paired-end libraries (Nextera XT), which were sequenced using the Illumina MiSeq instrument with $2 \times 300$ PE protocol (Illumina Inc, San Diego, California, United States). De novo assembly of reads was performed by SPAdes v3.8 (https:// w3.iss.it/site/aries/). Kp- $\mathrm{P}_{1}$ and $\mathrm{Kp}-\mathrm{P}_{2}$ genomes were released under Bioproject PRJNA667843.

$\mathrm{Kp}-\mathrm{P}_{1}$ and $\mathrm{Kp}-\mathrm{P}_{2}$ strains were assigned to $\mathrm{ST} 147$ by in silico multilocus sequence typing (MLST; https:// bigsdb.pasteur.fr/klebsiella/klebsiella.html), the same ST as the NDM-1-producing $K$. pneumoniae clone that caused a large outbreak in Tuscany in 2018-2019 [1,2]. A phylogenetic tree using parsimony was built based on single nucleotide polymorphisms (SNP) (kSNP v3.0; https://w3.iss.it/site/aries/) in Kp- $\mathrm{P}_{1}$ and $\mathrm{Kp}-\mathrm{P}_{2}$ genomes, as well as in 21 ST147 genomes of strains isolated in Pisa during the 2018-2019 outbreak and in 13 genomes of unrelated, internationally identified ST147 strains that were downloaded from GenBank.

ST147 sequences of recent and prior isolates in Pisa formed a cluster, which was distinct from epidemiologically unrelated ST147 sequences. Within the Pisa cluster, $\mathrm{Kp}-\mathrm{P}_{1}$ and $\mathrm{Kp}-\mathrm{P}_{2}$ formed a further group with a subset of strains (Kp-11Pi, Kp-12Pi and $\mathrm{Kp}-16 \mathrm{Pi})$ isolated in 2019. The sequences in this sub-cluster were highly related (Figure).

\section{Evolution of Klebsiella pneumoniae ST147 antimicrobial resistance}

The Kp- $\mathrm{P}_{1}$ and $\mathrm{Kp}-\mathrm{P}_{2}$ strains carried the bla ${ }_{\mathrm{NDM}-\mathrm{g}}$ gene, which presented one amino-acid substitution (E152K) with respect to bla ${ }_{\text {NDM-1 }}$ gene identified in 2018-2019 isolates. A complex array of plasmids was identified in $\mathrm{Kp}-\mathrm{P}_{1}$ and $\mathrm{Kp}-\mathrm{P}_{2}$ strains, including derivatives of the $p K p Q I L, p K P N_{3}, p N D M-M A R$ and IncR plasmids 
Phylogenetic tree to analyse ST147 Klebsiella pneumoniae sequences from isolates of two patients in Pisa, Italy, 2020 ( $\mathrm{n}=36$ sequences)

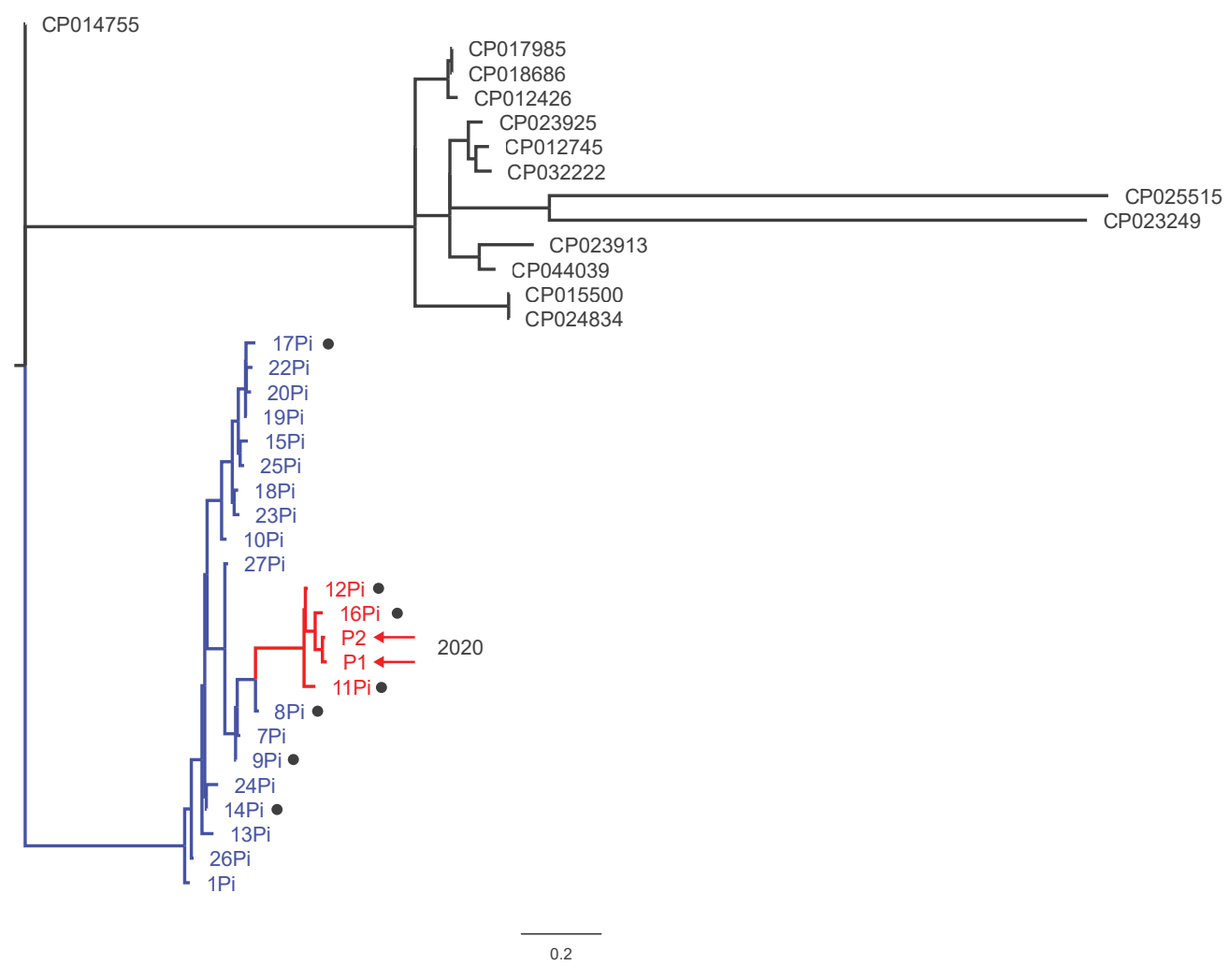

CDS: coding sequence; SNP: single nucleotide polymorphism; ST: sequence type.

All sequences analysed in the phylogenetic analysis are of ST147. The parsimony SNP analysis was performed by the kSNP3 (Galaxy version 3.1) Software at the ARIES public Galaxy server (https://w3.iss.it/site/aries/). The phylogenetic tree was visualised using the Fig Tree programme v. 1.4.3 (http://tree.bio.ed.ac.uk/software/figtree/). The phylogenetic tree was based on the sequences of Kp-P1 and Kp-P 2 genomes (highlighted by red arrows) as well as those of 34 genomes, including 21 from strains isolated during the $2018-2019$ outbreak in Pisa (in blue or red font) and 13 from epidemiologically-unrelated strains (in black). The sequences of the 13 unrelated strains were downloaded from GenBank (accession numbers are indicated on the tree leaves). Black dots indicate the seven genomes selected for protein alignment analysis (https://rast.nmpdr.org/seedviewer.cgi). Translations of the CDSs in these genomes were aligned to those of $\mathrm{Kp}-\mathrm{P}_{1}$ and $\mathrm{Kp}-\mathrm{P}_{2}$ genome CDSs for comparison. The scale bar indicates the extent of genetic change by estimating the average number of nucleotide substitutions per site.

(PlasmidFinder v2.1 [5]). It was not possible to obtain complete assembly of plasmids for these strains. No relevant differences were found in acquired resistance genes (Table 2, ResFinder v3.2 [6]) and replicon content, in particular comparing the two Kp-P1 and $\mathrm{Kp}-\mathrm{P}_{2}$ strains with the three closely related $\mathrm{Kp}-11 \mathrm{Pi}$, $\mathrm{Kp}-12 \mathrm{Pi}$ and $\mathrm{Kp}-16 \mathrm{Pi}$ strains. This observation suggested that the observed phenotypical variations in MICs for colistin ( $16 \mathrm{mg} / \mathrm{L}$ for Kp-1, Kp-2, Kp-12Pi and $\mathrm{Kp}-16 \mathrm{Pi}$ vs $<0.5 \mathrm{mg} / \mathrm{L}$ for the other five strains), fosfomycin $(>128 \mathrm{mg} / \mathrm{L}$ for $\mathrm{Kp}-1$ and $-2 \mathrm{vs} \leq 32 \mathrm{mg} / \mathrm{L}$ for the remaining strains) and tigecycline ( $2 \mathrm{mg} / \mathrm{L}$ for $\mathrm{Kp}-1$ and $-2 \mathrm{vs} \leq 1 \mathrm{mg} / \mathrm{L}$ for the other strains) were likely due to acquired chromosomal mutations rather than to horizontal transfer of additional plasmid-mediated resistance genes.

Protein basic local alignment search tool (BLASTP) analysis was performed on deduced coding sequences (CDSs) obtained by translation of $\mathrm{Kp}-\mathrm{P}_{1}$ and $\mathrm{Kp}-\mathrm{P}_{2}$ genomes (https://rast.nmpdr.org/seedviewer.cgi) in comparison with CDSs deduced from seven genomes, with different susceptibility to colistin, fosfomycin and tigecycline antibiotics (Table 1), which included also those of the three $\mathrm{Kp}-11 \mathrm{Pi}, \mathrm{Kp}-12 \mathrm{Pi}$ and $\mathrm{Kp}-16 \mathrm{Pi}$ strains.

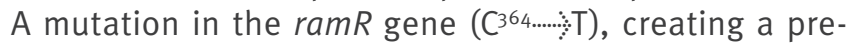
mature stop codon at position 122 was identified in $\mathrm{Kp}-\mathrm{P}_{1}, \mathrm{Kp}-\mathrm{P}_{2}, \mathrm{Kp}-11 \mathrm{Pi}, \mathrm{Kp}-12 \mathrm{Pi}$, and $\mathrm{Kp}-16 \mathrm{Pi}$ strains, respectively. The resistance antibiotic multiple $A$ regulator (RamR) protein is otherwise 194 amino acids in the wild type (GenBank accession number: ARJ36702.1). Ram $R$ has been reported to act as the negative regulator of resistance antibiotic multiple $A(\operatorname{Ram} A)$ that is the positive regulator of the AcrAB efflux pump system. Depletion of RamR results in constitutive activation of the efflux pump increasing MICs for tigecycline [7]. In this study, depletion of RamR increased tigecycline MICs from $0.25 \mathrm{mg} / \mathrm{L}$ (observed in strains with a wild type RamR) to $0.5 \mathrm{mg} / \mathrm{L}$ in strains $\mathrm{Kp}-11 \mathrm{Pi}$ and $\mathrm{Kp}-12 \mathrm{Pi}$, to $1 \mathrm{mg} / \mathrm{L}$ in strain $\mathrm{KP}-16 \mathrm{Pi}$ and to $2 \mathrm{mg} / \mathrm{L}$ in $\mathrm{Kp}-\mathrm{P}_{1}$ and 
TABLE 2

Genetic features of 2020-ST147 Klebsiella pneumoniae strains described in this study compared with six strains representative of the 2018-2019-ST147 outbreak, Pisa, Italy ( $=8$ strains)

\begin{tabular}{|c|c|c|c|c|c|}
\hline $\begin{array}{l}\text { Strain } \\
\text { SRA }\end{array}$ & Year & $\begin{array}{l}\text { Acquired } \\
\text { beta-lactamases }\end{array}$ & $\begin{array}{l}\text { Other acquired resistance } \\
\text { genes }\end{array}$ & Replicon content & $\begin{array}{l}\text { TygR, ColR, and FosR } \\
\text { chromosomal loci }\end{array}$ \\
\hline $\begin{array}{l}\text { Kp-P1 } \\
\text { SRR12785639 }\end{array}$ & 2020 & $\begin{array}{c}\text { NDM-9, CTX-M-15, } \\
\text { OXA-1, OXA-9, TEM-1A }\end{array}$ & $\begin{array}{c}\operatorname{armA}, \operatorname{aad} A_{1}, \operatorname{aac}\left(6^{\circ}\right)-I b, \\
\operatorname{aph}\left(3^{\circ}\right)-V I, \operatorname{aph}\left(3^{\circ}\right)-1 A, \operatorname{catB} 3, \\
d f r A 5, m p h(E), \operatorname{msr}(E), \text { qnrS1, } \\
\text { sul1, sul2 }\end{array}$ & $\begin{array}{l}\text { HI1B-FIB(pNDM-Mar); Fllk- } \\
\text { FIB(pKpQIL); FIB(pKpN3); R; } \\
\text { FIB(pKPHS1); Col(pHAD28); } \\
\text { ColRNAI }\end{array}$ & 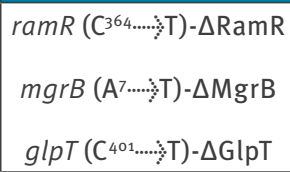 \\
\hline $\begin{array}{l}\text { Kp-P2 } \\
\text { SRR12785638 }\end{array}$ & 2020 & $\begin{array}{c}\text { NDM-9, CTX-M-15, } \\
\text { OXA-1, OXA-9, TEM-1A }\end{array}$ & $\begin{array}{c}\operatorname{armA}, \operatorname{aad} A_{1}, \operatorname{aac}\left(6^{\circ}\right)-l_{3}, \\
\operatorname{aph}\left(3^{\circ}\right)-V I, \operatorname{aph}\left(3^{\circ}\right)-1 A, \operatorname{catB} 3, \\
d f r A 5, m p h(E), \operatorname{msr}(E), \text { qnrS1, } \\
\text { sul1, sul2 }\end{array}$ & $\begin{array}{c}\text { HI1B-FIB(pNDM-Mar); Fllk- } \\
\text { FIB(pKpQIL); FIB(pKpN3); R; } \\
\text { N; FIB(pKPHS1); Col(pHAD28); } \\
\text { ColRNAI }\end{array}$ & 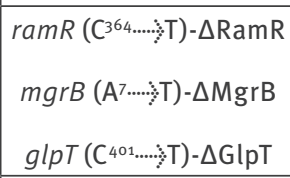 \\
\hline $\begin{array}{l}\text { Kp-8Pi } \\
\text { SRR12518027 }\end{array}$ & 2018 & $\begin{array}{c}\text { NDM-1, CTX-M-15, OXA- } \\
1, \text { OXA-9, TEM-1A }\end{array}$ & $\begin{array}{c}\operatorname{armA}, \operatorname{aad} A_{1}, \operatorname{aac}\left(6^{\circ}\right)-I b, \\
\operatorname{aph}\left(3^{\circ}\right)-V I, \operatorname{aph}\left(3^{\circ}\right)-1 A, \operatorname{catB} 3, \\
d f r A 5, m p h(E), \operatorname{msr}(E), \text { qnrS1, } \\
\text { sul1, sul2 }\end{array}$ & $\begin{array}{c}\text { HI1B-FIB(pNDM-Mar); } \\
\text { FIB(pKpQIL); R; FIB(pKPHS1) }\end{array}$ & $\begin{array}{l}\text { RamR wt } \\
\text { MgrB wt } \\
\text { GlpT wt }\end{array}$ \\
\hline $\begin{array}{l}\text { Kp-9Pi } \\
\text { SRR12518023 }\end{array}$ & 2018 & $\begin{array}{c}\text { NDM-1, CTX-M-15, OXA- } \\
1, \text { OXA-9, TEM-1A }\end{array}$ & $\begin{array}{c}\operatorname{armA}, \operatorname{aad} A_{1}, \operatorname{aac}\left(6^{\circ}\right)-I b, \\
\operatorname{aph}\left(3^{\circ}\right)-V I, \operatorname{aph}\left(3^{\circ}\right)-1 A, \operatorname{catB} 3, \\
d f r A 5, m p h(E), \operatorname{msr}(E), \operatorname{qnrS} 1, \\
\text { sul1, sul2 }\end{array}$ & $\begin{array}{c}\text { HI1B-FIB(pNDM-Mar); } \\
\text { FIB(pKpQIL); R; FIB(pKPHS1) }\end{array}$ & $\begin{array}{l}\text { RamR wt } \\
\text { MgrB wt } \\
\text { GlpT wt }\end{array}$ \\
\hline $\begin{array}{l}\text { Kp-11Pi } \\
\text { SRR12518041 }\end{array}$ & 2018 & $\begin{array}{c}\text { NDM-1, CTX-M-15, OXA- } \\
1, \text { OXA-9, TEM-1A }\end{array}$ & $\begin{array}{c}\operatorname{armA}, \operatorname{aad} A_{1}, \operatorname{aac}\left(6^{\circ}\right)-I b, \\
\operatorname{aph}\left(3^{\circ}\right)-V I, \operatorname{aph}\left(3^{\circ}\right)-1 A, \operatorname{catB} 3, \\
d f r A 5, m p h(E), \operatorname{msr}(E), \text { qnrS1, } \\
\text { sul1, sul2 }\end{array}$ & $\begin{array}{c}\text { HI1B-FIB(pNDM-Mar); } \\
\text { FIB(pKpQIL); FIlk-FIB(pKpN3); R; } \\
\text { FIB(pKPHS1) }\end{array}$ & $\begin{array}{c}\operatorname{ramR}\left(\mathrm{C}^{364 . . . . \mathrm{T})}\right)-\Delta \text { RamR } \\
\text { MgrB wt } \\
\text { GlpT wt }\end{array}$ \\
\hline $\begin{array}{l}\mathrm{Kp}-12 \mathrm{Pi} \\
\mathrm{SRR} 12518021\end{array}$ & 2019 & $\begin{array}{c}\text { NDM-1, CTX-M-15, OXA- } \\
\text { 1, OXA-9, TEM-1A }\end{array}$ & $\begin{array}{c}\operatorname{armA}, \operatorname{aad} A_{1}, \operatorname{aac}\left(6^{\circ}\right)-I b \\
\operatorname{aph}\left(3^{\circ}\right)-V I, \operatorname{aph}\left(3^{\circ}\right)-1 A, \operatorname{catB} 3, \\
d f r A 5, m p h(E), \operatorname{msr}(E), \text { qnrS1, } \\
\text { sul1, sul2 }\end{array}$ & $\begin{array}{c}\text { HI1B-FIB(pNDM-Mar); } \\
\text { FIB(pKpQIL); FIlk-FIB(pKpN3); R; } \\
\text { FIB(pKPHS1); ColRNAI }\end{array}$ & 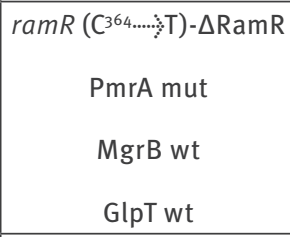 \\
\hline $\begin{array}{l}\mathrm{Kp}-14 \mathrm{Pi} \\
\mathrm{SRR} 12518062\end{array}$ & 2019 & $\begin{array}{c}\text { NDM-1, CTX-M-15, OXA- } \\
\text { 1, OXA-9, TEM-1A }\end{array}$ & $\begin{array}{c}\operatorname{armA}, \operatorname{aad} A_{1}, \operatorname{aac}\left(6^{\circ}\right)-I b, \\
\operatorname{aph}\left(3^{\circ}\right)-V I, \operatorname{aph}\left(3^{\circ}\right)-1 A, \operatorname{catB} 3, \\
d f r A 5, m p h(E), \operatorname{msr}(E), \text { qnrS1, } \\
\text { sul1, sul2 }\end{array}$ & $\begin{array}{c}\text { HI1B-FIB(pNDM-Mar); } \\
\text { FIB(pKpQIL); R; FIB(pKPHS1); } \\
\text { ColRNAI }\end{array}$ & $\begin{array}{l}\text { RamR wt } \\
\text { MgrB wt } \\
\text { GlpT wt }\end{array}$ \\
\hline $\begin{array}{l}\mathrm{Kp}-16 \mathrm{Pi} \\
\mathrm{SRR} 12518060\end{array}$ & 2019 & $\begin{array}{c}\text { NDM-1, CTX-M-15, OXA- } \\
\text { 1, OXA-9, TEM-1A }\end{array}$ & $\begin{array}{c}\operatorname{armA}, \operatorname{aad} A_{1}, \operatorname{aac}\left(6^{\circ}\right)-I b, \\
\operatorname{aph}\left(3^{\circ}\right)-V I, \operatorname{aph}\left(3^{\circ}\right)-1 A, \operatorname{catB} 3, \\
d f r A 5, m p h(E), \operatorname{msr}(E), \text { qnrS1, } \\
\text { sul1, sul2 }\end{array}$ & $\begin{array}{c}\text { HI1B-FIB(pNDM-Mar); } \\
\text { FIB(pKpQIL); Fllk-FIB(pKpN3); R; } \\
\text { FIB(pKPHS1); ColRNAI }\end{array}$ & 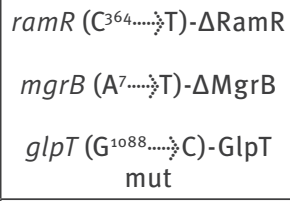 \\
\hline $\begin{array}{l}\mathrm{Kp}-17 \mathrm{Pi} \\
\mathrm{SRR} 12518059\end{array}$ & 2019 & $\begin{array}{c}\text { NDM-1, CTX-M-15, OXA- } \\
\text { 1, OXA-9, TEM-1B }\end{array}$ & $\begin{array}{c}\operatorname{armA}, \operatorname{aad} A_{1}, \operatorname{aac}\left(6^{\circ}\right)-I b, \\
\operatorname{aph}\left(3^{\circ}\right)-V I, \operatorname{aph}\left(3^{\circ}\right)-1 A, \operatorname{catB} 3, \\
d f r A 5, m p h(E), \operatorname{msr}(E), \text { anrS1, } \\
\text { sul1, sul2 }\end{array}$ & $\begin{array}{c}\text { Hl1B-FIB(pNDM-Mar); } \\
\text { FIB(pKpQIL); R; FIB(pKPHS1); X4 }\end{array}$ & $\begin{array}{l}\text { RamR wt } \\
\text { MgrB wt } \\
\text { GlpT wt }\end{array}$ \\
\hline
\end{tabular}

GIpT: glycerol-3-phosphate transporter; mut: mutation; NDM: New Delhi metallo-beta-lactamase; OXA: oxacillinase; PmrA: multi-drug resistance efflux pump PmrA; RamR: resistance antibiotic multiple (Ram)A regulator; SRA: Sequence Read Archive accession number at the National Center for Biotechnology Information database (NCBI; https://www.ncbi.nlm.nih.gov/); ST: sequence type; wt: wild type.

$\mathrm{Kp}-\mathrm{P}_{1}$ and $\mathrm{Kp}-\mathrm{P}_{2}$ are the $K$. pneumoniae strains derived from patient 1 and patient 2 , in 2020 in Pisa, who are described in this study. The rest of the strains in the table are representative of the 2018-2019 outbreak in Pisa.

$\mathrm{Kp} \Delta$ is used when mutations caused premature termination of translation of the deduced protein sequence. Mut indicates that the deduced protein sequence is mutated with respect to the wt amino-acid sequence. 
$\mathrm{Kp}-\mathrm{P}_{2}$ strains (Table 1 ). MIC differences observed among ramR mutants were likely due to additional mutations in the $\mathrm{Kp}-\mathrm{P}_{1}$ and $\mathrm{Kp}-\mathrm{P}_{2}$ genomes that were not identified in this study.

A mutation $\left(A^{7} \cdots . . .5 T\right)$ in the $m g r B$ gene created a premature stop codon and the complete depletion of the MgrB protein (GenBank accession number: QDC86160.1), the regulator of phoP gene expression, in colistin-resistant $\mathrm{Kp}-\mathrm{P}_{1}, \mathrm{Kp}-\mathrm{P}_{2}$ and $\mathrm{Kp}-16 \mathrm{Pi}$ strains, respectively (Tables $1,2)[8]$. A substitution $G 53 \mathrm{~V}$ was identified in the PmrA protein (reference GenBank nr. KDM30728) of the other colistin resistant $\mathrm{Kp}-12 \mathrm{Pi}$ strain (Table 1 ). No $\mathrm{mcr}$ genes were detected in the genomes under investigation.

Fosfomycin resistance in $\mathrm{Kp}-\mathrm{P}_{1}$ and $\mathrm{Kp}-\mathrm{P}_{2}$ was due to a mutation in the $g l p T$ gene creating a premature stop codon at position 134 (wild type glycerol-3-phosphate transporter (GIpT) is 448 amino acids; GenBank accession number: KLY15715) causing the depletion of the GIpT (Table 2). Defects in one of two GlpT or uptake hexose phosphate (UhpT) transporters lead to reduced fosfomycin uptake into the bacterial cells causing increasing MICs for this antibiotic $[9,10]$. A substitution S79L was also found in the hexose-phosphate uptake two-component transcriptional response regulator UhpA protein in $\mathrm{Kp}-\mathrm{P}_{1}$ and -2 strains. No mutations were found in MurA, UhpT, FosA, CyaA, Crp, Ptsl, UhpB and UhpC proteins related to fosfomycin importation and metabolism [11-13].

\section{Discussion}

A total of 1,645 cases with NDM-carbapenem-resistant Enterobacteriaceae (CRE)-positive microbiological samples were identified in the period from 1 November 2018 to 31 October 2019 in Tuscany [1]. In the same period, at the University Hospital of Pisa 705 patients were colonised or infected by CRE, and among them 388 were reported as testing positive for NDM-CRE (data not shown). The outbreak in Tuscany was dominated by the $K$. pneumoniae ST147 clone $(1,495$ isolates; $90.9 \%$ ), characterised by the presence of the bla ${ }_{\text {NDM-1 }}$ gene $[1,2]$. Data from the Pisa University Hospital showed that $98 \%$ of NDM-producing strains were $K$. pneumoniae. The outbreak was controlled but some sporadic cases occurred in Tuscany later in 2019 [1]. The outbreak clone was resistant to almost all beta-lactam antibiotics, including expanded-spectrum cephalosporins, carbapenems, beta-lactamase inhibitor combinations, aztreonam, and aminoglycosides. Susceptibility to colistin and fosfomycin was detected in most of the isolates collected during the outbreak. The combination CAZ-AVI/ATM resulted synergistic in vitro and associated with clinical benefit $[2,14]$.

In this study, we describe the resistance genetic features of XDR ST147 K. pneumoniae strains isolated in 2020. These isolates were genetically related to the 2018-2019 outbreak clone, but had the NDM-9 instead of the NDM-1 carbapenemase variant, with no apparent changes in beta-lactam susceptibility. Mutations in chromosomally encoded genes conferred resistance to tigecycline, fosfomycin and colistin. From a clinical perspective, the 2020 strains represent a new variant, which may become a notable challenge for clinicians, because of the extended resistant profile.

The new variant likely emerged from a subgroup of highly related ST147 strains from the 2018-2019 outbreak. These strains harboured mutations in RamR and MgrB proteins, implicated in tigecycline and colistin resistance, respectively. In particular, the RamR depletion detected in three of the strains, coincided, in one of them, with the MgrB depletion, similar what is observed for the new variant. RamR followed by MgrB protein depletions may have been intermediate steps in the evolution of the variant. The acquired fosfomycin resistance appears to be the most novel characteristic of the emerging ST147 variant and appeared associated with a defect in the GlpT. Few K. pneumoniae strains have been reported with this fosfomycin resistance mechanism [13], therefore it represents an interesting case of resistance evolution. Further investigation is needed to understand in which setting and by which combination therapy this XDR clone has been selected.

The persistence of $K$. pneumoniae ST147 isolation suggests that this clone can be considered as endemic in the Pisa University Hospital and there is risk of spread to other hospitals in Tuscany and elsewhere. Several actions, such as systematic screening of hospitalised patients, contact precautions, and cohorting of colonised/infected patients are ongoing to contain the spread of this clone.

Data availability

$\mathrm{Kp}-\mathrm{P}_{1}$ and $\mathrm{Kp}-\mathrm{P}_{2}$ genomes have been released under Bioproject PRJNA667843

\section{Acknowledgements}

We are sincerely grateful to Prof. Gian Maria Rossolini, University of Florence and Dr. Vincenzo Di Pilato, University of Genoa, who kindly provided us with 21 genome sequences used in this study for genomic comparison, obtained from strains isolated at the University Hospital of Pisa during the 2018-2019 outbreak.

\section{Conflict of interest}

$M$. F. received grants and/or speaker honoraria from MSD, Angelini, Shionogi, Pfizer, Menarini and Nordic Pharma. F. M. has participated in advisory board and/or received speaker honoraria from Angelini, Correvio, Merck Sharp \& Dohme (MSD), Nordic Pharma, Pfizer, Astellas, Gilead, Bristol-Myers Squibb (BMS), Janssen, ViiV, bioMérieux, Biotest, Becton Dickinson, Pfizer, and Shionogi. Declared conflicts of interest did not affect scientific objectivity of this study. The other authors have none to declare.

Authors' contributions 
MF conceived the study and wrote the manuscript; CG collected data, performed the experimental investigation and wrote the manuscript; SB performed experiments and revised manuscript; GT collected data; AL performed experiments; PM and FM were involved in patient assistance and revised the manuscript; $A C$ coordinated experimental design, performed data analysis and wrote the manuscript.

\section{References}

1. Tavoschi L, Forni S, Porretta A, Righi L, Pieralli F, Menichetti $F$, et al. , On Behalf Of The Tuscan Clinical Microbiology Laboratory Network. Prolonged outbreak of New Delhi metallo-beta-lactamase-producing carbapenem-resistant Enterobacterales (NDM-CRE), Tuscany, Italy, 2018 to 2019. Euro Surveill. 2020;25(6):2000085. https://doi.org/10.2807/15607917.ES.2020.25.6.2000085 PMID: 32070467

2. Falcone M, Tiseo G, Antonelli A, Giordano C, Di Pilato $\mathrm{V}$, Bertolucci $P$, et al. Clinical features and outcomes of bloodstream infections caused by New Delhi metallo- $\beta$ lactamase-producing Enterobacterales during a regional outbreak. Open Forum Infect Dis. 2020;7(2):ofa011. https:// doi.org/10.1093/ofid/ofaa011 PMID: 32042848

3. European Committee on Antimicrobial Susceptibility Testing (EUCAST). Breakpoint tables for interpretation of MICs and zone diameters. Version 10.0. Växjö: EUCAST; 2020. [Accessed 26 Nov 2020]. Available from: http://www.eucast.org

4. Yasmin M, Fouts DE, Jacobs MR, Haydar H, Marshall SH, White $\mathrm{R}$, et al. Monitoring ceftazidime-avibactam and aztreonam concentrations in the treatment of a bloodstream infection caused by a multidrug-resistant Enterobacter sp. carrying both Klebsiella pneumoniae carbapenemase-4 and New Delhi metallo- $\beta$-lactamase-1. Clin Infect Dis. 2020;71(4):1095-8. https://doi.org/10.1093/cid/ciz1155 PMID: 31802119

5. Carattoli A, Zankari E, Garcia-Fernandez A, Voldby Larsen $M$, Lund $O$, et al. In silico detection and typing of plasmids using PlasmidFinder and Plasmid Multilocus Sequence Typing. Antimicrob Agents Chemother. 2014;58(7):3895-903. https:// doi.org/10.1128/AAC.02412-14 PMID: 24777092

6. Zankari E, Hasman H, Cosentino S, Vestergaard M, Rasmussen $\mathrm{S}$, Lund $\mathrm{O}$, et al. Identification of acquired antimicrobial resistance genes. J Antimicrob Chemother. 2012;67(11):2640-4. https://doi.org/10.1093/jac/dks261 PMID: 22782487

7. Villa L, Feudi C, Fortini D, García-Fernández A, Carattoli A. Genomics of KPC-producing Klebsiella pneumoniae sequence type 512 clone highlights the role of RamR and ribosomal S10 protein mutations in conferring tigecycline resistance. Antimicrob Agents Chemother. 2014;58(3):1707-12. https:// doi.org/10.1128/AAC.01803-13 PMID: 24379204

8. Giordano C, Barnini S, Tsioutis C, Chlebowicz MA, Scoulica EV, Gikas A, et al. Expansion of KPC-producing Klebsiella pneumoniae with various mgrB mutations giving rise to colistin resistance: the role of ISL3 on plasmids. Int J Antimicrob Agents. 2018;51(2):260-5. https://doi.org/10.1016/j. ijantimicag.2017.10.011 PMID: 29097338

9. Giske CG. Contemporary resistance trends and mechanisms for the old antibiotics colistin, temocillin, fosfomycin, mecillinam and nitrofurantoin. Clin Microbiol Infect. 2015;21(10):899-905. https://doi.org/10.1016/j.cmi.2015.05.022 PMID: 26027916

10. Castañeda-García A, Blázquez J, Rodríguez-Rojas A. Molecular mechanisms and clinical impact of acquired and intrinsic fosfomycin resistance. Antibiotics (Basel). 2013;2(2):217-36. https://doi.org/10.3390/antibiotics2020217 PMID: 27029300

11. Takahata S, Ida T, Hiraishi T, Sakakibara S, Maebashi K, Terada $\mathrm{S}$, et al. Molecular mechanisms of fosfomycin resistance in clinical isolates of Escherichia coli. Int J Antimicrob Agents. 2010;35(4):333-7. https://doi.org/10.1016/j. ijantimicag.2009.11.011 PMID: 20071153

12. Cordaro JC, Melton T, Stratis JP, Atagün M, Gladding C, Hartman $\mathrm{PE}$, et al. Fosfomycin resistance: selection method for internal and extended deletions of the phosphoenolpyruvate:sugar phosphotransferase genes of Salmonella typhimurium. Bacteriol. 1976;128(3):785-93. https://doi.org/10.1128/ JB.128.3.785-793.1976 PMID: 186449

13. Lu PL, Hsieh YJ, Lin JE, Huang JW, Yang TY, Lin L, et al. Characterisation of fosfomycin resistance mechanisms and molecular epidemiology in extended-spectrum $\beta$-lactamaseproducing Klebsiella pneumoniae isolates. Int J Antimicrob Agents. 2016;48(5):564-8. https://doi.org/10.1016/j. ijantimicag.2016.08.013 PMID: 27765412

14. Falcone M, Daikos GL, Tiseo G, Bassoulis D, Giordano C, Galfo $\mathrm{V}$, et al. Efficacy of Ceftazidime-avibactam Plus Aztreonam in Patients With Bloodstream Infections Caused by Metallo$\beta$-lactamase-Producing Enterobacterales. Clin Infect Dis.
2020; ciaa586. https://doi.org/10.1093/cid/ciaa586 PMID: 32427286

License, supplementary material and copyright

This is an open-access article distributed under the terms of the Creative Commons Attribution (CC BY 4.0) Licence. You may share and adapt the material, but must give appropriate credit to the source, provide a link to the licence and indicate if changes were made.

Any supplementary material referenced in the article can be found in the online version.

This article is copyright of the authors or their affiliated institutions, 2020. 